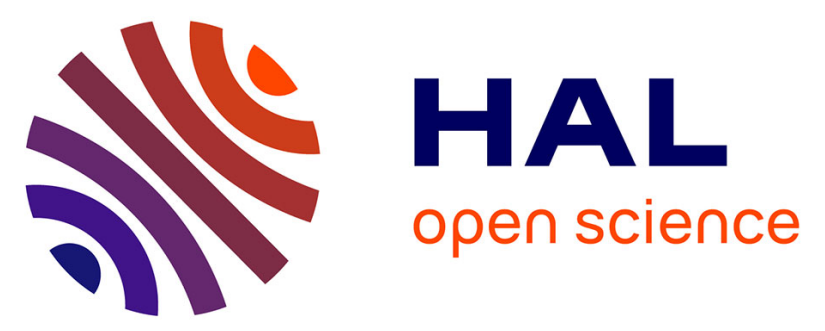

\title{
The role of cerebrospinal fluid 14-3-3 and other proteins in the diagnosis of sporadic Creutzfeldt-Jakob disease in the United Kingdom: a 10 year review
}

Gurjit Chohan, Catherine Pennington, Jan M Mackenzie, Mary M Andrews, Dawn Everington, Robert G Will, Richard Sg Knight, Alison Je Green

\section{To cite this version:}

Gurjit Chohan, Catherine Pennington, Jan M Mackenzie, Mary M Andrews, Dawn Everington, et al.. The role of cerebrospinal fluid 14-3-3 and other proteins in the diagnosis of sporadic Creutzfeldt-Jakob disease in the United Kingdom: a 10 year review. Journal of Neurology, Neurosurgery and Psychiatry, 2010, 81 (11), pp.1243. 10.1136/jnnp.2009.197962 . hal-00578412

\section{HAL Id: hal-00578412 \\ https://hal.science/hal-00578412}

Submitted on 20 Mar 2011

HAL is a multi-disciplinary open access archive for the deposit and dissemination of scientific research documents, whether they are published or not. The documents may come from teaching and research institutions in France or abroad, or from public or private research centers.
L'archive ouverte pluridisciplinaire HAL, est destinée au dépôt et à la diffusion de documents scientifiques de niveau recherche, publiés ou non, émanant des établissements d'enseignement et de recherche français ou étrangers, des laboratoires publics ou privés. 
The role of cerebrospinal fluid 14-3-3 and other proteins in the diagnosis of sporadic Creutzfeldt-Jakob disease in the United Kingdom: a 10 year review

G Chohan, C Pennington, JM Mackenzie, M Andrews, D Everington, RG Will, RSG Knight, AJE Green

The National CJD Surveillance Unit, University of Edinburgh, Western General Hospital, Crewe Road, Edinburgh EH4 2XU

Corresponding author: $\quad$ Dr AJE Green

The National CJD Surveillance Unit

University of Edinburgh

Western General Hospital

Crewe Road

Edinburgh EH4 2XU

Tel no: + 44 (0) 1315373075

Fax no: + 44 (0) 1313431404

E-mail: Alison.Green@ed.ac.uk

$\begin{array}{ll}\text { Words: } & 3,009 \\ \text { References: } & 17 \\ \text { Tables: } & 6 \\ \text { Figures: } & 3\end{array}$

Keywords: Cerebrospinal fluid, Creutzfeldt-Jakob disease, 14-3-3, S100b, tau protein 
The Corresponding Author has the right to grant on behalf of all authors and does grant on behalf of all authors, an exclusive licence (or non exclusive for government employees) on a worldwide basis to the BMJ Publishing Group Ltd to permit this article (if accepted) to be published in JNNP and any other BMJPGL products and sublicences such use and exploit all subsidiary rights, as set out in our licence. (http://group.bmj.com/products/journals/instructionsfor-authors/licence-forms)

\section{ABSTRACT}

It is 10 years since the detection of cerebrospinal fluid (CSF) 14-3-3 was included in the diagnostic criteria for sporadic Creutzfeldt-Jakob disease (sCJD) by the World Health Organisation. Since that time other CSF proteins, such as S100b and tau protein have been proposed as surrogate markers for SCJD. We aimed to investigate the diagnostic value of each of these three proteins. CSF samples collected from patients who were referred to the National CJD Surveillance Unit as suspected cases of sCJD during the period 1997 - 2007 were analysed for 14-3-3, S100b and tau protein. The sensitivity, specificity, positive predictive value (PPV) and negative predictive value (NPV) of each of these markers either alone or in combination for the diagnosis of SCJD were assessed. The impact of CSF 14-3-3 analysis on the case classification of sCJD was investigated. CSF 14-3-3 had the greatest sensitivity (86\%) when compared to tau protein $(81 \%)$ and S100b $(65 \%)$. The combination of a positive CSF 14-3-3 or an elevated tau protein with a raised S100b had the highest positive predictive power for sCJD. During the study period 100 patients were classified as probable sCJD solely on the basis of the clinical features and a positive CSF 14-3-3. The most sensitive marker for SCJD was a positive CSF 14-3-3. The analysis of CSF 14-3-3 plays a crucial role in the case classification of sCJD. 


\section{INTRODUCTION}

Creutzfeldt-Jakob disease belongs to a family of fatal neurodegenerative diseases collectively known as human transmissible spongiform encephalopathies. Sporadic CJD (sCJD) remains the most prevalent form worldwide with an annual incidence of 1.01.5/million/year.[1] Human spongiform encephalopathies are characterised by the accumulation of pathological prion protein $(\mathrm{PrP})$ in the central nervous tissue. The pathological isoform is termed $\mathrm{PrP}^{\mathrm{Sc}}$ and this differs from the normal cellular isoform by its high content of $\beta$ - sheet structure and partial resistance to protease digestion.[2] Additional histological changes identified include spongiosis, neuronal loss and gliosis. Neuropathological studies remain the only means of obtaining a definitive diagnosis; the initial diagnosis however is still dependent on the clinical phenotype, as defined by the WHO criteria.[3]. Marked phenotypic heterogeneity is well documented in all human prion diseases and in SCJD this observation is yet to be explained. Early experimental transmission studies on primates,[4] subsequent epidemiological studies [5,6] and isolated case reports have allowed diagnostic criteria to be refined over the years, however early diagnosis and in turn accurate surveillance remains a challenge. Atypical forms of SCJD are well recognized, it has been postulated that such variation is partially dependent on, or associated with, genetic and molecular factors, PRNP codon 129 genotype and prion protein isotype respectively. The typical short duration disease phenotype being linked to methionine homozygosity and $\mathrm{PrP}^{\mathrm{Sc}}$ type 1.[2] The atypical and rarer variants (those defined as having a long duration of illness, young age of onset and unusual clinical or pathological features) are linked to valine homozygosity or heterozygosity at codon 129 and $\operatorname{PrP}^{\mathrm{Sc}}$ type 2 .

The advent of novel diagnostic tests, specifically the cerebrospinal fluid (CSF) 14-3-3 protein, has also allowed improvement in classification over the last decade. The 14-3-3 has better diagnostic utility than investigative tests such as the EEG.[7,8] However the sensitivity of CSF 14-3-3 has been shown to vary, partially dependent on the genetic and molecular influences described above.[9] The detection of CSF 14-3-3 remains a supportive tool in the appropriate clinical context but as a solitary test, independent of clinical phenotype, has little value.

The major differential diagnoses of SCJD remain those of other irreversible neurodegenerative conditions; however a small proportion of patients may have a 
potentially treatable condition. Therefore CSF analyses, such as cell count and total protein, are an important early investigation in these patients and CSF 14-3-3 is often performed at this time. Many conditions associated with acute neuronal damage may result in a positive CSF 14-3-3 and thereby reduce the specificity of CSF 14-3-3 for sCJD. [8] Therefore other brain-specific proteins in the CSF may be of value as diagnostic markers. These additional markers include the CSF astrocytic marker S100b and the neuronal marker tau, protein in isolation or in combination.

In this study we aim to firstly review the sensitivity and specificity of each CSF protein in SCJD and also review the potential role of a combination of several markers to improve sensitivity and specificity in the clinical diagnosis of sCJD. Secondly, the impact of the CSF 14-3-3 on UK surveillance is of great importance and is therefore considered, specifically reviewing the number of cases of probable sCJD classified on the basis of CSF 14-3-3. In addition those cases classified as a probable case of SCJD on the basis of a positive 14-3-3 but found to have an alternative pathological diagnosis are investigated. The additional role of combining neuronal markers in order to potentially exclude sCJD is reviewed.

\section{MATERIALS AND METHODS}

\section{Patients}

The National CJD Surveillance Unit (NCJDSU) was established in May 1990 to prospectively identify and record all suspected cases of sporadic CJD in the UK. The primary aim of the programme was to detect any change in the epidemiology of the disease that might be attributable to bovine spongiform encephalopathy, and a distinct clinical-pathological phenotype was described in 1996 (variant CJD). Global surveillance of CJD has continued within the UK and active surveillance has improved due to strong collaborations with the neuroscience community. Patients are referred and where possible visited in life. A detailed history of the current illness and past medical history, including potential risk exposure is undertaken. Each case is further investigated by clinical examination and review of clinical investigations. Investigative tests which are potentially supportive for a diagnosis of SCJD such as an EEG and MRI are reviewed by a member of the NCJDSU. The NCJDSU acts as a referral centre for CSF 14-3-3 analysis throughout the UK 
During the period 1997 and 2007 inclusive, 245 cases of neuropathologically confirmed sCJD[10] (117 female, 128 male aged 27-87 years (mean $65.8 \pm 9.7$ years) at notification), 163 cases of clinically probable sCJD[3] (82 female, 81 male aged 41-92 years (mean $68.0 \pm 9.8$ years) at notification) and 171 disease control cases (86 female, 85 male aged 28-89 years (mean $66.4 \pm 11.4$ years) at notification) who had CSF 14-3-3 analysis were identified for this study. Cases classified as not suffering from CJD (disease control cases) included those with a pathologically proven alternative diagnosis or those provided with an alternative clinical diagnosis by either the clinical team or by a member of the NCJDSU (Table 1).

Table 1 Disease control cases (pathologically proven alternative diagnosis or alternative clinical diagnosis)

\begin{tabular}{|c|c|}
\hline Alternative pathological proven diagnosis & Number of cases \\
\hline Alzheimer's disease & 14 \\
\hline Biopsy/post-mortem showed no evidence of CJD & $12 *$ \\
\hline Malignancy/Paraneoplastic syndrome & $10 * *$ \\
\hline Lewy body dementia & 4 \\
\hline Cerebral lymphoma & 4 \\
\hline Encephalitis & 4 \\
\hline Parkinson's disease & 4 \\
\hline Cerebrovascular disease & 3 \\
\hline Alzheimer's disease and ischaemic change & 3 \\
\hline Alzheimer's disease and Lewy body dementia & 3 \\
\hline Progressive multifocal leucoencephalopathy & 1 \\
\hline Normal pressure hydrocephalus & 1 \\
\hline Fronto-temporal dementia & 1 \\
\hline Corticostriatal degenerative disease & 1 \\
\hline Demyelination & 1 \\
\hline Alternative Clinical Diagnosis & Number of cases \\
\hline Dementia (unknown etiology) or clinically not CJD & 22 \\
\hline Clinically improved with or without steroids & 22 \\
\hline Alzheimer's disease & 18 \\
\hline Cerebrovascular disease/cerebral vasculitus & 9 \\
\hline Fronto-temporal dementia & 7 \\
\hline Lewy body dementia & 6 \\
\hline Paraneoplastic syndrome & 6 \\
\hline Psychiatric disorder & 4 \\
\hline
\end{tabular}




\begin{tabular}{|c|l|}
\hline Huntington's disease & 3 \\
\hline Hashimoto's encephalitis & 2 \\
\hline Corticobasal degeneration & 2 \\
\hline Multi-system atrophy & 1 \\
\hline Granulomatous disease & 1 \\
\hline Central pontine myelinolysis & 1 \\
\hline Serotonin syndrome & 1 \\
\hline
\end{tabular}

*1 patient clinically not thought to have had CJD and post mortem conducted but brain tissue not examined

** 1 patient had a western blot for $\mathrm{PrP}^{\mathrm{Sc}}$ which was negative, clinically this patient is thought to have a paraneoplastic process

\section{CSF protein analysis}

CSF samples are sent to the laboratory on dry ice and stored at $-80^{\circ} \mathrm{C}$ prior to analysis. For this study CSF 14-3-3, S100b and tau protein were analysed. Protein 14-3-3 in CSF was detected by western blotting after SDS-polyacrylamide gel electrophoresis (SDSPAGE) with chemiluminescent visualization.[11-13] A positive, negative and two weak positive 14-3-3 controls were included on each run. These were controls from patients with neuropathologically confirmed sporadic CJD (positive control) or from patients with either a clinical or pathological diagnosis of an alternative disease (negative and weak positive controls). The relative immunoreactivity of positive, negative and weak positive 14-3-3 CSF samples is given in fig 1. The blots were independently assessed by two people (AJEG, MA, GC or CP) and only positive CSF 14-3-3 results were used for case classification. CSF S100b was measured using a previously reported sandwich enzyme linked immunosorbant assay (ELISA).[11] A concentration of $<0.5 \mathrm{ng} / \mathrm{ml}$ was considered to be normal, whilst a concentration of $>1.0 \mathrm{ng} / \mathrm{ml}$ was considered to be diagnostic. CSF tau protein was measured using an enzyme immunoassay (Innotest hTAU-Ag, Innogenetics, Ghent, Belgium), according to the manufacturer's recommendations. A concentration of $>1260 \mathrm{pg} / \mathrm{ml}$ was considered to be diagnostic.[14] This assay measures total tau protein concentrations and as such measures both normally phosphorylated tau and hyper-phosphorylated tau. Some CSF samples had insufficient volume for all three analytes to be measured. 


\section{$P R N P$ codon 129 genotype and PrP isotyping}

Prion protein isotyping was performed on all suspected cases of prion disease where fresh brain tissue was received by the NCJDSU. Small quantities of cerebral cortex were homogenized, treated with proteases and the size and abundance of the three $\mathrm{PrP}^{\mathrm{Sc}}$ glycoforms was determined by Western blot analysis.[15] Genotyping for polymorphism at codon 129 of the PRNP gene was carried out on all available blood specimens. DNA was extracted from blood using standard techniques and analysed using the Helsinki method.[16]

\section{Statistical analysis}

Comparison of age by Mann Whitney tests was carried out. Descriptive statistics were calculated for the SCJD and control patients. The sensitivity, specificity, positive predictive value (PPV), negative predictive value (NPV) and efficiency of each marker and for combinations of markers were obtained. To investigate the influence of stage of disease on the sensitivity of CSF 14-3-3 and tau protein, we divided the disease duration for each patient into equal thirds. The stage in which the LP was performed was noted and the sensitivity of each marker for SCJD in each of the three stages was calculated.

\section{RESULTS}

The sensitivity, specificity, PPV, NPV and efficiency of each neuronal marker for the diagnosis of neuropathologically confirmed SCJD cases are shown in Table 2. CSF 14-3-3 is the most sensitive marker and has a higher sensitivity than CSF tau, $86 \%$ and $81 \%$ respectively. CSF S100b does not have adequate sensitivity $(65 \%)$ to be used as an isolated marker of SCJD. The difference in sensitivity between CSF 14-3-3 and tau protein is not influenced by the different numbers of cases investigated for each analyte. The sensitivity of CSF 14-3-3 and tau protein calculated using those samples where both analytes were measured is $85 \%$ and $81 \%$ respectively. The specificity of CSF $14-3-3$ and tau protein in those samples where both analytes were measured is $74 \%$ and $85 \%$ respectively. 
Table 2 The sensitivity, specificity, positive predictive value (PPV), negative predictive value (NPV) and efficiency for each marker and combination of CSF markers in neuropathologically confirmed sCJD. Figures in parentheses are 95\% confidence limits.

\begin{tabular}{|c|c|c|c|c|c|c|c|}
\hline & $\mathbf{1 4 - 3 - 3}$ & Tau & S100b & $\begin{array}{c}\mathbf{1 4 - 3 - 3} \\
\text { and } \\
\text { S100b }\end{array}$ & $\begin{array}{c}\text { Tau } \\
\text { and } \\
\text { S100b }\end{array}$ & $\begin{array}{c}\mathbf{1 4 - 3 - 3} \\
\text { and } \\
\text { Tau }\end{array}$ & $\begin{array}{c}\mathbf{1 4 - 3 - 3 , ~ T a u} \\
\text { and } \\
\text { S100b }\end{array}$ \\
\hline sCJD $^{\mathbf{1}}$ & $210 / 245$ & $175 / 216$ & $158 / 243$ & $151 / 242$ & $127 / 216$ & $162 / 216$ & $123 / 216$ \\
\hline Not sCJD & $44 / 171$ & $20 / 135$ & $17 / 169$ & $9 / 169$ & $7 / 135$ & $16 / 135$ & $6 / 135$ \\
\hline Sensitivity & $86 \%$ & $81 \%$ & $65 \%$ & $62 \%$ & $59 \%$ & $75 \%$ & $57 \%$ \\
$(81,90)$ & $(75,86)$ & $(59,71)$ & $(57,69)$ & $(52,65)$ & $(69,81)$ & $(50,64)$ \\
\hline Specificity & $74 \%$ & $84 \%$ & $90 \%$ & $95 \%$ & $95 \%$ & $88 \%$ & $96 \%$ \\
$(67,81)$ & $(78,91)$ & $(84,94)$ & $(90,98)$ & $(90,98)$ & $(81,93)$ & $(91,98)$ \\
\hline PPV & $83 \%$ & $90 \%$ & $90 \%$ & $94 \%$ & $95 \%$ & $91 \%$ & $95 \%$ \\
$(77,87)$ & $(85,94)$ & $(85,94)$ & $(90,97)$ & $(90,98)$ & $(86,95)$ & $(90,98$ \\
\hline NPV & $78 \%$ & $74 \%$ & $64 \%$ & $64 \%$ & $59 \%$ & $69 \%$ & $58 \%$ \\
$(71,84)$ & $(66,80)$ & $(58,70)$ & $(58,70)$ & $(52,66)$ & $(61,76)$ & $(51,65)$ \\
\hline Efficiency & $81 \%$ & $83 \%$ & $75 \%$ & $76 \%$ & $73 \%$ & $80 \%$ & $72 \%$ \\
$(77,85)$ & $(78,86)$ & $(71,79)$ & $(72,80)$ & $(68,77)$ & $(75,84)$ & $(67,76)$ \\
\hline
\end{tabular}

${ }^{1}$ The figures given are the number of positive or negative results over the total number of samples investigated, Efficiency was defined as: True positives + True negatives

Total number tested

The combination of a positive CSF 14-3-3 with either an elevated S100b or an elevated tau protein increased the PPV of 14-3-3 from $83 \%$ to $94 \%$ or $91 \%$, respectively (Table 2 and fig 2a,b). Likewise the combination of an elevated tau protein and an elevated S100b resulted in a higher PPV (95\%) for SCJD when compared to using each marker alone (Table 2, fig 2c). However combining the tests either in pairs or taking all three markers together resulted in a reduction in sensitivity and a reduction in the efficiency of each marker. That is to say the ability of each marker to distinguish between those patients with SCJD and those that present with symptoms similar to SCJD but turn out to have an alternative diagnosis is reduced if they are combined (Table 2).

In the atypical subgroups, although the numbers are small, CSF 14-3-3 is more sensitive than an elevated tau (Table 3). This finding is particularly noticeable in those patients 
who are 50 years or less at the onset of the disease. However, in those SCJD cases that were negative for either CSF 14-3-3 or tau protein there did not seem to be a difference in the demographics of the patients or any obvious effect of codon 129 and $\mathrm{PrP}^{\mathrm{Sc}}$ isotype. In the 14-3-3 negative group there were $35 \mathrm{sCJD}$ cases (27-81 years (mean $62.0 \pm 10.9$ years) at notification) and in the tau negative group there were 41 sCJD cases (44-81 years (mean $63.3 \pm 9.9$ years) at notification). The disease duration was also comparable 2-54 months (mean $15.1 \pm 11.7$ months) and 2-54 months (mean $14.4 \pm 12.2$ months) respectively. These disease durations are much longer than those in SCJD cases who are positive for CSF 14-3-3 (mean $6.6 \pm 6.8$ months) or CSF tau protein (mean $6.5 \pm 6.6$ months).

Table 3 Effect of age at onset of disease, disease duration and PRNP-codon 129 genotype on the sensitivity of CSF 14-3-3 and Tau protein.

\begin{tabular}{|c|c|c|}
\hline & $\mathbf{1 4 - 3 - 3}(\boldsymbol{\%})$ & Tau protein $(\boldsymbol{\%})$ \\
\hline \multirow{2}{*}{$\mathbf{5 0}$ years at onset disease } & $12 / 17(71 \%)$ & $10 / 16(62 \%)$ \\
& $(44,90)$ & $(35,84)$ \\
\hline \multirow{2}{*}{$\mathbf{5 0}$ years at onset disease } & $198 / 228(87 \%)$ & $165 / 200(83 \%)$ \\
& $(82,91)$ & $(77,87)$ \\
\hline \multirow{2}{*}{$\mathbf{1 2}$ months disease duration } & $23 / 41(56 \%)$ & $21 / 39(54 \%)$ \\
\hline \multirow{2}{*}{$\mathbf{1 2}$ months disease duration } & $(40,72)$ & $(37,70)$ \\
\hline \multirow{2}{*}{ PRNP Codon 129-MM } & $(88,199(92 \%)$ & $151 / 175(86 \%)$ \\
\hline PRNP Codon 129-MV & $(80,121(88 \%)$ & $(80,91)$ \\
\hline PRNP Codon 129-VV & $32 / 44(73 \%)$ & $(77,91)$ \\
\hline & $(57,85)$ & $(50,39(67 \%)$ \\
\hline
\end{tabular}

Results expressed as number of positives over total number investigated. Figures in parentheses are the sensitivity of the individual marker in each subset of SCJD. The 95\% confidence limits are given on the second row.

The effect of stage of disease on the sensitivity of CSF 14-3-3 and tau protein is shown in Table 4. The time of the LP and the date of the onset of disease were only available in 209 patients. Only $7 \%$ of patients had an LP within the first stage of disease, whilst $42 \%$ and $51 \%$ of patients had CSF samples taken in the second and third stages of disease 
respectively. Both CSF 14-3-3 and tau protein show comparable sensitivity in the first two stages of disease, however in the final stage of the disease CSF 14-3-3 is more sensitive than CSF tau protein.

Table 4 Influence of time of CSF sampling on CSF 14-3-3 and tau protein positive results.

\begin{tabular}{|l|c|c|}
\hline \multicolumn{1}{|c|}{ Stage of disease } & $\mathbf{1 4 - 3 - 3}(\boldsymbol{\%})$ & Tau protein $(\boldsymbol{\%})$ \\
\hline First stage $\mathbf{( 0 - 3 3 \%}$ disease duration) & $9 / 14(64 \%)$ & $10 / 14(71 \%)$ \\
& $(35,87)$ & $(42,92)$ \\
\hline Second stage (34-66\% disease duration) & $73 / 88(83 \%)$ & $72 / 88(82 \%)$ \\
& $(73,90)$ & $(72,89)$ \\
\hline Third stage (67-100\% of disease duration) & $97 / 107(91 \%)$ & $89 / 107(83 \%)$ \\
& $(83,95)$ & $(75,90)$ \\
\hline
\end{tabular}

The time of the LP was calculated by expressing the time of LP from disease onset as a percentage of the total disease duration. The patients were classified into 3 groups depending on whether they had CSF samples taken in the first, second or third stage of the disease. Results expressed as number of positives over total number investigated. The $95 \%$ confidence limits are given on the second row.

During the study period 21 patients had a weak positive CSF 14-3-3. Of the 21 patients with weak positive CSF 14-3-3 results, 9 patients had neuropathologically confirmed sCJD whilst the remaining 12 patients had Alzheimer' disease (3), Lewy body disease (2), no neuropathological evidence of CJD (2), frontal lobe degeneration (1), epilepsy (1), multi-focal leukoencephalopathy (1), angiotrophic lymphoma (1) and no further information could be obtained on the final diagnosis in the remaining patient.

The most specific individual marker was CSF S100b however it also had the poorest sensitivity which limits its use as an isolated marker. CSF tau protein had a greater specificity than CSF 14-3-3 protein (85\% vs 74\%). Analysis of the control cases that had a positive CSF 14-3-3 and/or an elevated CSF tau protein showed that the most prevalent diagnoses included Alzheimer's disease, paraneoplastic syndrome and patients who clinically improved without an alternative diagnosis (Table 5). 
Table 5 Diagnoses in disease controls with positive CSF 14-3-3 and elevated tau protein cases

\begin{tabular}{|c|c|c|}
\hline Diagnosis (14-3-3 positive) & Pathological (26) & Clinical (18) \\
\hline Alzheimer's disease & $7 *$ & 2 \\
\hline Malignancy/Paraneoplastic & 5 & 1 \\
\hline Improved/ no evidence of CJD & $3 * *$ & 7 \\
\hline Encephalitis/limbic encephalitis & 3 & 2 \\
\hline Lewy Body Dementia & 1 & 0 \\
\hline Parkinson's disease & 1 & 0 \\
\hline Cerebrovascular disease & 0 & $2 * * *$ \\
\hline B cell Lymphoma/cerebral lymphoma & 3 & 0 \\
\hline Fronto-temporal Dementia & 0 & 1 \\
\hline Vasculitis & 0 & 1 \\
\hline Central pontine myelinolysis & 0 & 1 \\
\hline Multifocal demyelination & 1 & 0 \\
\hline Anoxic brain injury & 1 & 0 \\
\hline Normal pressure hydrocephalus & 1 & 0 \\
\hline Corticobasal degeneration & 0 & 1 \\
\hline Diagnosis (tau protein $>1260 \mathrm{pg} / \mathrm{ml}$ ) & Pathological (12) & Clinical (6) \\
\hline Alzheimer's disease & 3 & 1 \\
\hline Malignancy/paraneoplastic & 3 & 0 \\
\hline Improved or no evidence of CJD & 1 & 1 \\
\hline Fronto-temporal Dementia & 0 & 1 \\
\hline Corticobasal degeneration & 0 & 1 \\
\hline Encephalitis & 0 & 1 \\
\hline Lymphoma & 1 & 0 \\
\hline Cerebrovascular disease & $1 * * *$ & 1 \\
\hline Multi focal demyelination & 1 & 0 \\
\hline Lewy body disease & 1 & 0 \\
\hline Anoxic brain damage & 1 & 0 \\
\hline
\end{tabular}

*three had evidence of additional cerebrovascular disease and two also had evidence of LBD

** one did not have brain examined

***one had evidence of Alzheimer's disease

Out of a total of 242 cases of SCJD which had both CSF 14-3-3 and S100b measured only 10 had a negative $14-3-3$ and a normal S100b concentration of $<0.5 \mathrm{ng} / \mathrm{ml}$. Likewise out of 216 sCJD cases that had both CSF tau protein and S100b measured only 14 had concentrations of both markers within the normal range (fig $3 a, b)$ 
The impact of CSF 14-3-3 on UK surveillance over the last decade was assessed by examining the number of clinically probable cases classified as a result of a positive CSF alone. 163 probable cases that died without post mortem examination were identified. No information regarding whether an EEG had been performed was available in 25 cases. Of the remaining 138 cases, 3 had no EEG performed and 135 had an EEG reviewed by a senior member of the NCJDSU. Of these 135 patients, 38 had an EEG classified as highly suggestive or typical and hence appropriate for use in classification. The remaining 97 were classified as probable with the aid of a positive CSF 14-3-3 (72\%). Therefore over the study period at least 100 patients were classified as having probable SCJD on the basis of CSF 14-3-3 alone. Sixty-nine patients initially classified as probable sCJD on the basis of a positive 14-3-3 alone, with either an unsupportive or unobtainable EEG, had subsequent post-mortem examination. Neuropathological confirmation of SCJD was obtained in 66 of these cases. The remaining three cases were misclassified as probable SCJD but in fact had pathological confirmation of carcinomatosis of the meninges (14-3-3 positive, S100b $0.57 \mathrm{ng} / \mathrm{ml}$, tau protein $3201 \mathrm{pg} / \mathrm{ml}$ ) and Lewy body dementia (14-3-3 positive, S100b 0.57ng/ml, tau protein $1170 \mathrm{pg} / \mathrm{ml}$ ) and Alzheimer's disease (14-3-3 positive, S100b 0.94ng/ml, tau protein $1294 \mathrm{pg} / \mathrm{ml})$. This gives a misclassification rate of $4 \%$.

\section{DISCUSSION}

It is ten years since a positive CSF 14-3-3 was added to the WHO diagnostic criteria for classifying probable SCJD. Since that time many studies have reported poorer sensitivity and specificity of CSF 14-3-3 than initially described, and have suggested that other markers of neuronal damage such as tau protein perform better. We have examined the diagnostic utility of CSF 14-3-3, tau protein and S100b analysis in the investigation of patients with suspected SCJD over a ten year period. In addition we have examined the overall impact that the inclusion of a positive CSF 14-3-3 has made on the diagnosis sCJD since it was introduced in 1997.

The sensitivity of a positive 14-3-3 in our study of SCJD is $86 \%$, which is higher than that of tau protein $(81 \%)$. The difference in sensitivity is more marked in the atypical forms of SCJD such as those who are younger than 50 years old at the onset of disease. In these cases the sensitivity of CSF $14-3-3$ is $71 \%$ compared to $62 \%$ for CSF tau protein. This supports the findings of a larger European-wide study that found a positive CSF 14-3-3 
was more sensitive than CSF tau protein in atypical sCJD cases.[9] CSF 14-3-3 is also more sensitive than CSF tau protein in the final stage of disease. This is important as this the time at which the majority of CSF samples are taken.

A CSF S100b concentration of greater than $1.0 \mathrm{ng} / \mathrm{ml}$ increases the PPV of a positive CSF 14-3-3 from $83 \%$ to $94 \%$, and an elevated CSF tau protein from $90 \%$ to $95 \%$. CSF $\mathrm{S} 100 \mathrm{~b}$ is routinely analysed by the NCJDSU for this reason. CSF S100b is also useful in excluding disease, with a negative CSF 14-3-3 and CSF S100b concentration of less than $0.5 \mathrm{ng} / \mathrm{ml}$ having a NPV of $88 \%$. Normal concentrations of CSF tau protein and CSF S100b concentration of less than $0.5 \mathrm{ng} / \mathrm{ml}$ have a NPV of $84 \%$.

There are no differences in the age of onset of disease, disease duration or codon 129 status of SCJD patients who are negative for CSF 14-3-3 and those that are negative for CSF tau. Therefore it is unlikely that the additional measurement of CSF tau will help improve the identification of CSF 14-3-3 negative sCJD cases.

Less than half the patients with weak positive CSF 14-3-3 results have sCJD and this suggests that the diagnostic utility of weak positive 14-3-3 results is limited. However, a repeat CSF 14-3-3 analysis in this group of patients may be of value if the clinical circumstances warrant it.[9]

Elevated CSF tau protein has a better specificity for sCJD than CSF 14-3-3 (84\% vs $74 \%$ ). This is a similar finding to a recently published study where tau protein was felt to be the single best marker for SCJD with a specificity of 90\%.[17] It is however important to note that the diagnostic test accuracy and the differences reported by these various studies is partially dependent on the cut-off concentration of tau protein used. A universally agreed level for tau protein is not currently available. The diagnoses in the non CJD cases were similar for both tests. It is unclear why CSF tau protein should be of greater specificity than 14-3-3. The factors influencing the release of neuronal proteins in CJD and other conditions are not fully understood. Many studies have investigated the sensitivity of these two markers for the diagnosis of SCJD but very few have compared their specificity. Indeed specificity is highly dependent on the population investigated and therefore it is very difficult to compare individual studies. However the population 
investigated in this study is highly selected and consists of patients where the preceding pre-test probability of SCJD is high.

During the ten years since its introduction CSF 14-3-3 analysis has enabled 100 patients in the UK with suspected SCJD who died without a post-mortem and without supportive EEG data to be classified as probable sCJD. During this time only three patients have been mis-classified as probable sCJD on the basis of a positive CSF 14-3-3.

We conclude that within the UK population referred with a clinical suspicion of SCJD to the NCJDSU over the last decade, brain derived proteins such as 14-3-3, S100b and tau have immense diagnostic value (see conclusion Table 6). In our experience, the combination of 14-3-3 and S100b remains the best predictor of supporting or excluding SCJD as a diagnosis when employed in an alogorithmic manner using 14-3-3 detection as the primary screening marker before utilizing the S100b result. The importance of interpreting these results in the appropriate clinical context however is vital, especially as the phenotypic heterogeneity of SCJD remains wide.

Table 6 Conclusions regarding the use of CSF 14-3-3 and other markers in the diagnosis of $S C J D$

CSF 14-3-3 as a sole marker has the highest sensitivity, particularly in the final stage of disease. As a sole marker CSF tau has the greatest specificity.

A combination of CSF 14-3-3 and elevated S100b or elevated tau protein and S100b has a greater PPV than CSF 14-3-3 alone

The combination of CSF 14-3-3 and tau protein in CSF 14-3-3 negative sCJD cases has not been shown to be of any additional value, even in phenotypically atypical cases

The combination of a negative CSF 14-3-3 and S100b is of value as a potential means of excluding sCJD

The differential diagnosis of SCJD in the 14-3-3 positive non-CJD cases remains as documented in previous studies

\section{ACKNOWLEDGEMENTS}

Surveillance of CJD is dependent on the co-operation of neurologists and neuropathologists throughout the UK. The authors are particularly grateful to the relatives of the patients for their co-operation and in particular to the relatives of the patient reported in this case report for their 
consent to publish. The CJD Surveillance Unit is funded by the Department of Health and the Scottish Home Office Department of Health.

\section{CONFLICTS OF INTEREST}

We have no conflicts of interest

\section{LEGENDS}

Figure 1

A western blotting illustrating the presence of positive, weak positive and negative CSF 14-3-3. Lanes 1, 2, 3 are positive for CSF 14-3-3, lanes 4, 5, 6 are weakly positive for CSF 14-3-3 and lanes 7, 8 and 9 are negative for CSF 14-3-3. Lanes 1 and 2 are from two patients with sporadic Creutzfeldt-Jakob disease (CJD), lanes 3 and 4 are from patients who have had a stroke and the remaining lanes contain CSF samples from patients who do not have CJD.

\section{REFERENCES}

1 Ladogana A, Puopolo M, Croes EA et al. Mortality from Creutzfledt-Jakob disease and related disorders in Europe, Australia and Canada. Neurology 2005;64(9):1586-91

2 Prusiner SB. Prions. Proc Natl Acad Sci USA 1998;95(23):13363-83

3 World Health Organisation. Report of a WHO consultation on global surveillance, diagnosis and therapy of human transmissible spongiform encephalopathies. Geneva, Switzerland: WHO, February 1998

4 Gibbs CJ, Gajduseck DC Asher DM, et al. Creutzfeldt-Jakob disease: transmission to the chimpanzee. Science 1968;161:388-9

5 Will RG, Alperovitch A, Poser S, et al. Descriptive epidemiology of Creutzfeldt-Jakob disease in six European countries, 1993-1995. Ann Neurol 1998;43:763-767

6 Brown P, Cathala F, Gajdusek DC: Creutzfeldt-Jakob disease in France: Epidemiological study of 170 patients dying during the decade 1968-1977. Ann Neurol 1979;6:438-446

7 Zerr I, Pocchiari M, Collins S, et al. Analysis of EEG and CSF 14-3-3 proteins as aids to the diagnosis of Creutzfeldt-Jakob disease. Neurology 2000;55:811815

8 Collins S, Sanchez-Juan P, Masters CL, et al. Determinants of diagnostic investigation sensitivities across the clinical spectrum of sporadic CreutzfeldtJakob disease. Brain 2006;129:2278-2287 
9 Sanchez-Juan P, Green A, Ladogana A et al. CSF test in the differential diagnosis of Creutzfeldt-Jakob disease. Neurology 2006;67:637-643

10 Ritchie D and Ironside J. Clinical and Neuropathological Investigations in Creutzfeldt-Jakob disease. Adv Clin Neurosci Rehabilitation: 2006;5:620-22

11 Green A, Thompson EJ, Stewart GE et al. Use of 14-3-3 and other brain specific proteins in CSF in the diagnosis of variant Creutzfeldt-Jakob disease. J Neurol Neurosurg Psychiatry 2001;70:744-748

12 Zerr I, Bodemer M, Gefeller O et al. Detection of 14-3-3 protein in the cerebrospinal fluid supports the diagnosis of Creutzfeldt-Jakob disease. Ann Neurol 1998;43:32-40

13 Hsich G, Kenney K, Gibbs CJ et al. The 14-3-3 Brain Protein in Cerebrospinal Fluid as a Marker for Transmissible Spongiform Encephalopathies. N Engl J Med 1996;335:924-930

14 Satoh K, Shirabe S, Eguchi $\mathrm{H}$, et al: 14-3-3 protein, total tau and phosphorylated tau in cerebrospinal fluid of patients with Creutzfeldt-Jakob disease and neurodegenerative disease in Japan. Cell Mol Neurobiol 2006;26: $45-52$

15 Hill A, Joiner S, Wadsworth JDF et al. Molecular classification of sporadic Creutzfeldt-Jakob disease. Brain 2003;126:1333-1346

16 Nurmi MH, Bishop M, Strain L et al. The normal population distribution of PRNP codon 129 polymorphism. Acta Neurol Scand 2003;108:374-378

17 Bahl JM, Heegaard N, Falkenhorst $G$ et al. The diagnostic efficiency of biomarkers in sporadic Creutzfeldt-Jakob disease compared to Alzheimer's disease. Neurobiology of Aging 2009;30(11):1834-41 
$\begin{array}{lllllllll}1 & 2 & 3 & 4 & 5 & 6 & 7 & 8 & 9\end{array}$ 
Figure 2a The role of a positive 14-3-3 and a diagnostic S100b in the diagnosis of SCJD

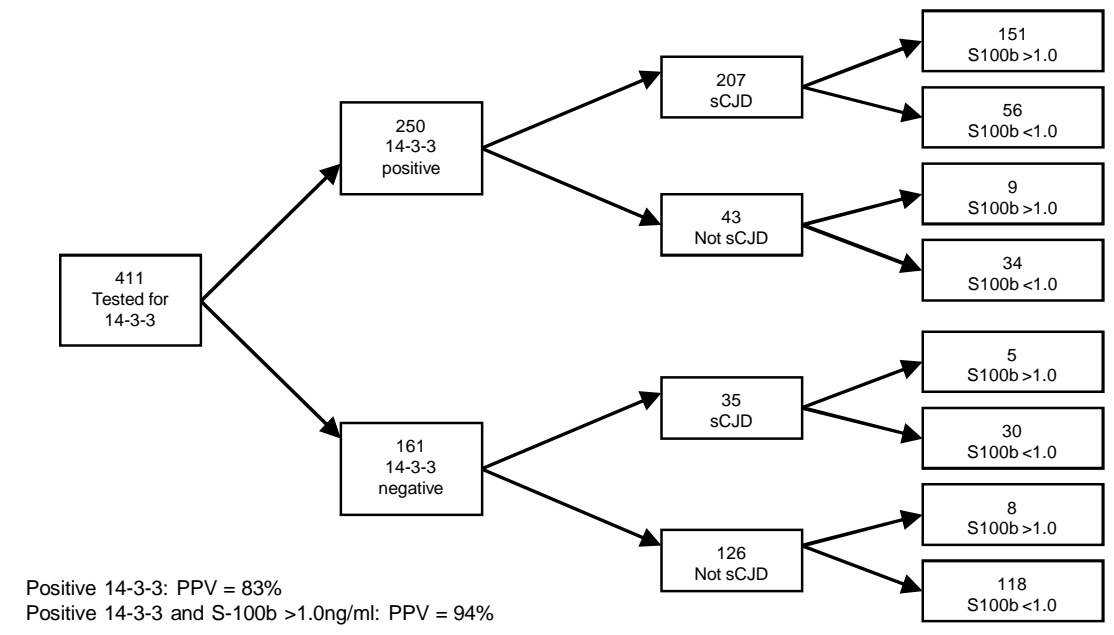

Figure $\mathbf{2} \mathbf{b}$ The role of a positive 14-3-3 and an elevated tau protein in the diagnosis of SCJD

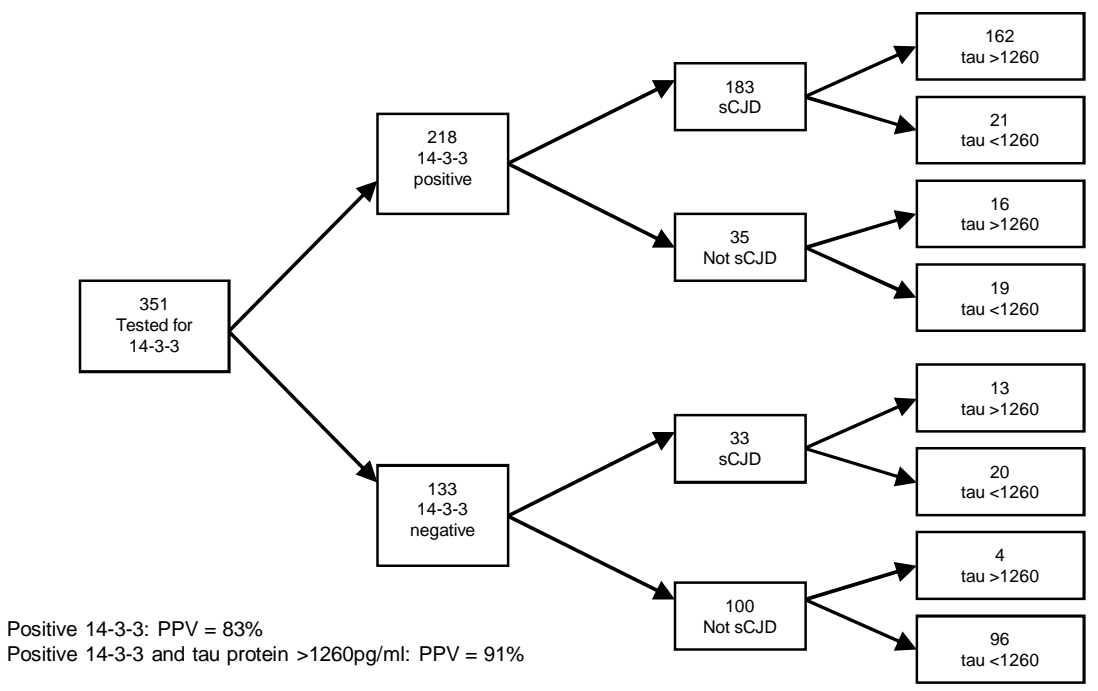

Figure 1c The role of a positive tau protein and an elevated S100b in the diagnosis of SCJD

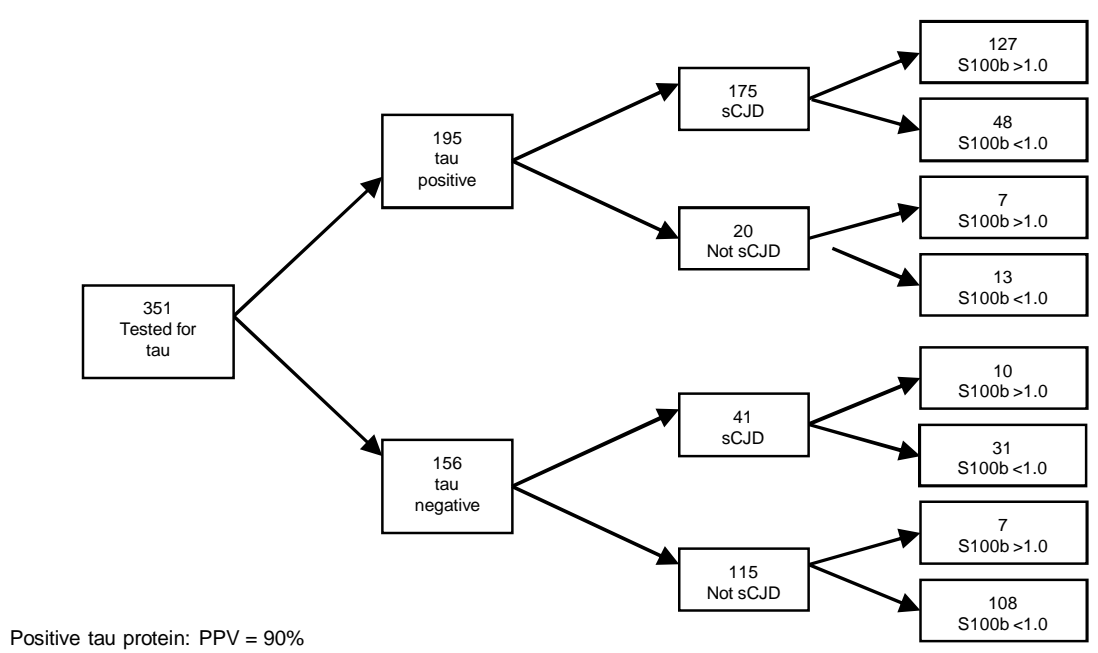

Positive tau protein: PPV $=90 \%$

Positive tau protein and positive S-100b: PPV $=95 \%$ 
Figure 3a The role of a negative 14-3-3 and normal S100b in the diagnosis of SCJD

Negative 14-3-3 (161)

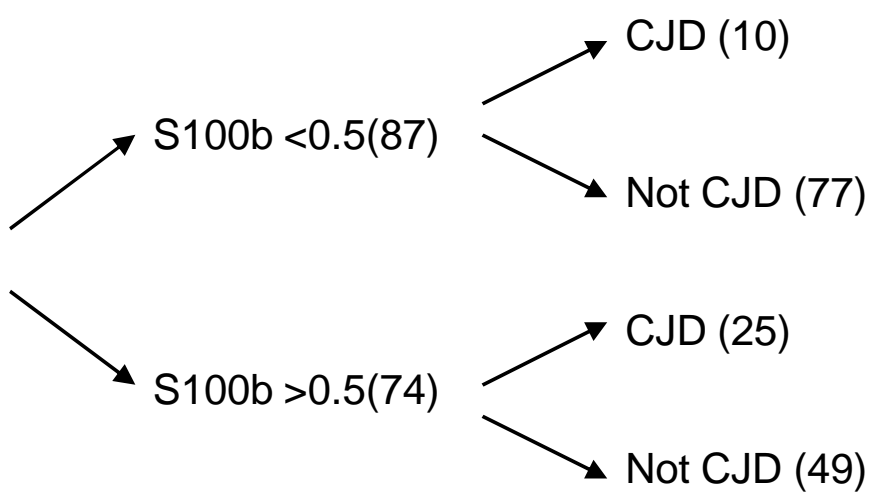

Negative 14-3-3: NPV $=78 \%$

Negative 14-3-3 and normal S100b: NPV $=88 \%$

Figure $3 \mathbf{b}$ The role of a negative tau protein and a normal S100b in excluding SCJD

Negative tau protein (156)

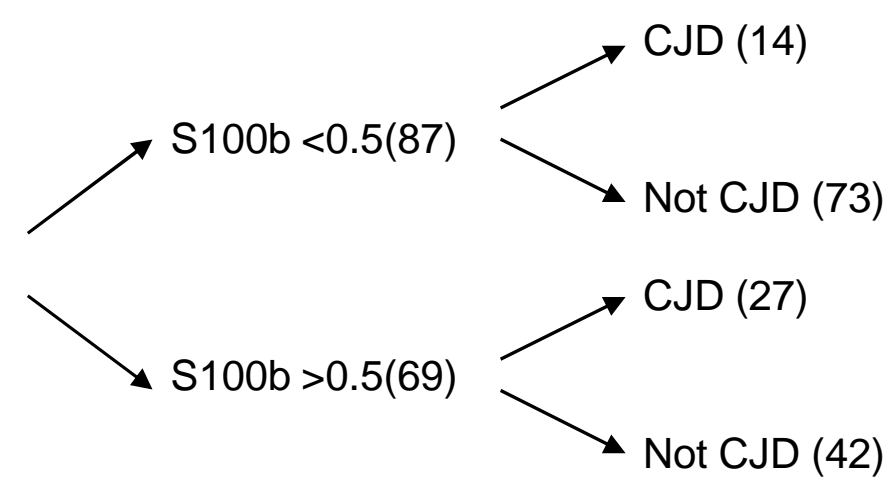

Negative tau protein: NPV $=74 \%$

Negative tau protein and normal S100b: NPV $=84 \%$ 
